\title{
Papillary Carcinoma of the Thyroglossal Duct Cyst: A Case Report and Review of Literature
}

\author{
Manish Munjal, Bhawna Garg, Neena Sood, Vikram Bhardwaj
}

\begin{abstract}
Papillary carcinoma arising in thyroglossal cyst is rare and is usually detected on postoperative histopathology after routine Sistrunk operation. Further management is a matter of debate and the choice lies between regular follow-up after Sistrunk operation or total thyroidectomy with or without radioiodine ablation and thyroxine suppression therapy. Here, we present a case of papillary carcinoma of thyroglossal duct cyst in a 26year-old lady. Papillary carcinoma was detected after a routine Sistrunk operation was done for a seemingly innocuous thyroglossal cyst. A total thyroidectomy was carried 1 week later followed by hormone replacement therapy to suppress serum thyroid-stimulating hormone levels.
\end{abstract}

Keywords: Papillary carcinoma, Thyroglossal duct cyst, Sistrunk operation.

How to cite this article: Munjal M, Garg B, Sood N, Bhardwaj V. Papillary Carcinoma of the Thyroglossal Duct Cyst: A Case Report and Review of Literature. Int J Otorhinolaryngol Clin 2013;5(3):148-150.

\section{Source of support: Nil}

Conflict of interest: None declared

\section{INTRODUCTION}

The thyroglossal duct cyst is the most common anomaly in thyroid development. The possibility of malignancy within the thyroglossal duct remnants are 1 to $2 \% .^{1}$ Till date, around 260 cases have been described in the literature. The first case was reported by Ucherman in $1915 .^{2}$ The most common histopathological type is papillary adenocarcinoma, accounting for roughly 85 to $92 \%$ of these tumors. ${ }^{3}$ It is followed by squamous cell carcinoma which accounts for about $7 \%$ of cases which tend to be more aggressive with worse prognosis.

In most of the cases the diagnosis of the thyroglossal duct carcinoma is made after the histopathologic examination of the surgical specimen of a routine Sistrunk procedure. $^{4}$

Here, we report a case of a 26 years old woman with papillary carcinoma of thyroglossal duct cyst.

\section{CASE REPORT}

A 26-year-old female patient was admitted to the Department of Otolaryngology, Head and Neck Surgery, Dayanand Medical College and Hospital, Ludhiana, Punjab, with circumscribed swelling in front of neck. On physical examination there was a $2 \times 2 \mathrm{~cm}^{2}$ smooth, painless, cystic nodule at the level of thyrohyoid membrane. The mass was mobile on deglutition and protrusion of tongue. The thyroid gland was normal on palpation and there was no cervical lymphadenopathy. Fine-needle aspiration cytology (FNAC) of the swelling was consistent with thyroglossal cyst. Thyroid profile was within normal limits. Ultrasonography of neck revealed a slightly hypoechoic midline neck mass with normal thyroid parenchyma. A radioiodine nuclear study was undertaken to confirm the existence of normal functioning thyroid gland. A diagnosis of thyroglossal duct cyst was made.

Sistrunk operation was performed with excision of the duct from foramen cecum to thyroid isthmus along with the body of hyoid bone. No infiltration of tissues surrounding the cyst or duct at the time of surgery was noted (Figs 1A to C).

The postoperative course was uneventful and the patient was discharged on 2nd day after surgery.

Histopathology report revealed a focus of papillary carcinoma within the cystic space. Areas of normal thyroid follicles were seen in the cyst wall (Figs 2A and B).

A total thyroidectomy was performed 1 week later followed by thyroxine suppression therapy. The thyroid gland showed no evidence of malignancy on histopathological examination.

\section{DISCUSSION}

During 3rd to 4th week of gestation, thyroid anlage forms at the foramen cecum of the tongue which descends downwards as a diverticulum to its adult location anterior to the thyroid cartilage by the 7th week. This diverticulum is known as thyroglossal duct. Normally, this duct obliterates, but if it remains patent, it may form a cyst which may be found anywhere from foramen cecum to the thyroid isthmus. Although these thyroglossal cysts are the most frequent midline neck masses in childhood, carcinoma arising in thyroglossal cysts is rare with only about 260 reported cases.

The most common type found is papillary carcinoma followed by squamous cell carcinoma. Mixed papillary squamous cell carcinoma and Hurthle cell carcinoma have been reported with extreme rarity. Medullary carcinoma has never been reported and understandably so as these arise from parafollicular C cells which are embryologically unrelated to thyroid. 

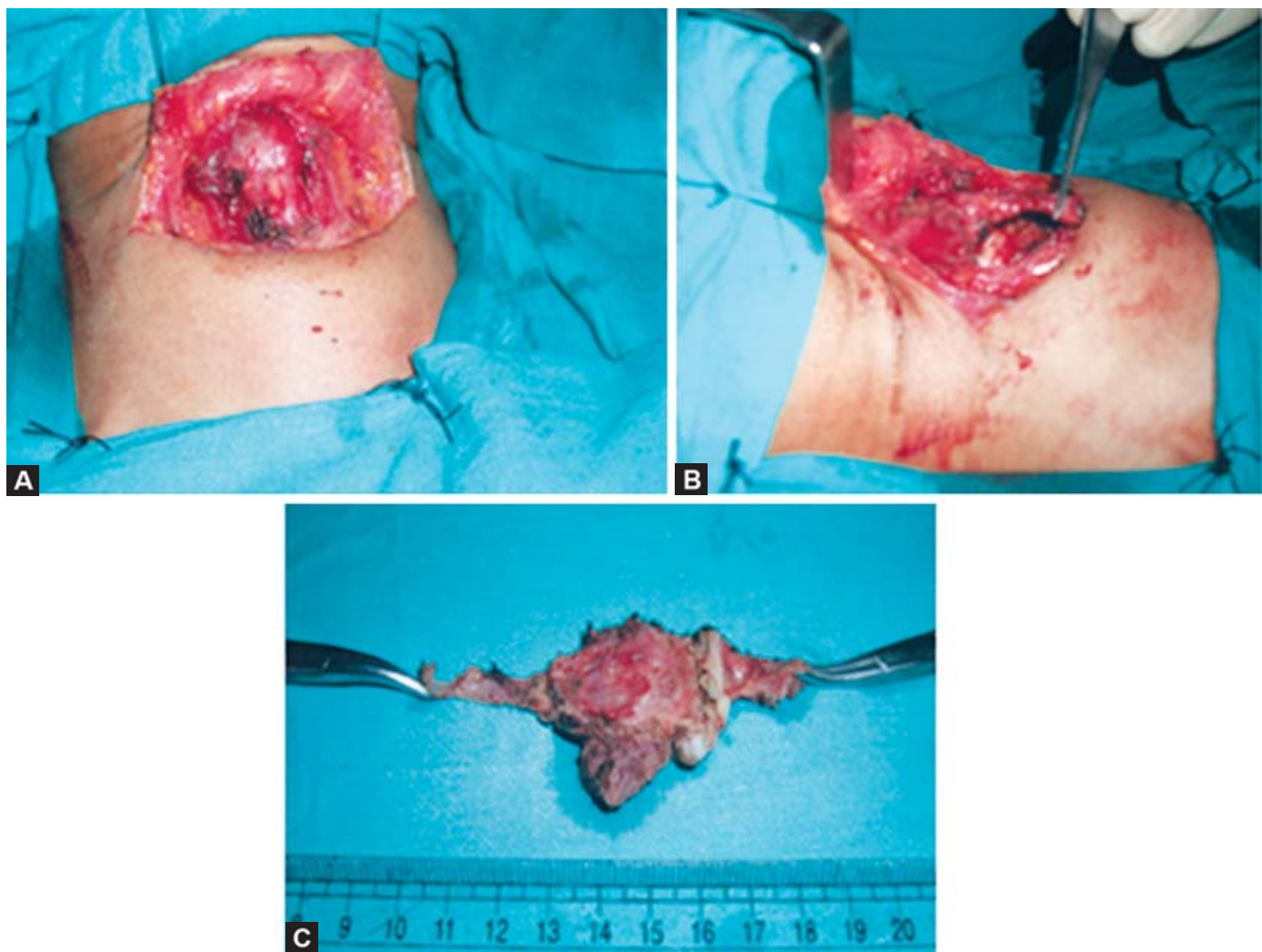

Figs 1A to C: (A) Thyroglossal duct cyst being isolated, (B) thyroglossal duct extending from the cyst to thyroid isthmus, $(C)$ excised specimen
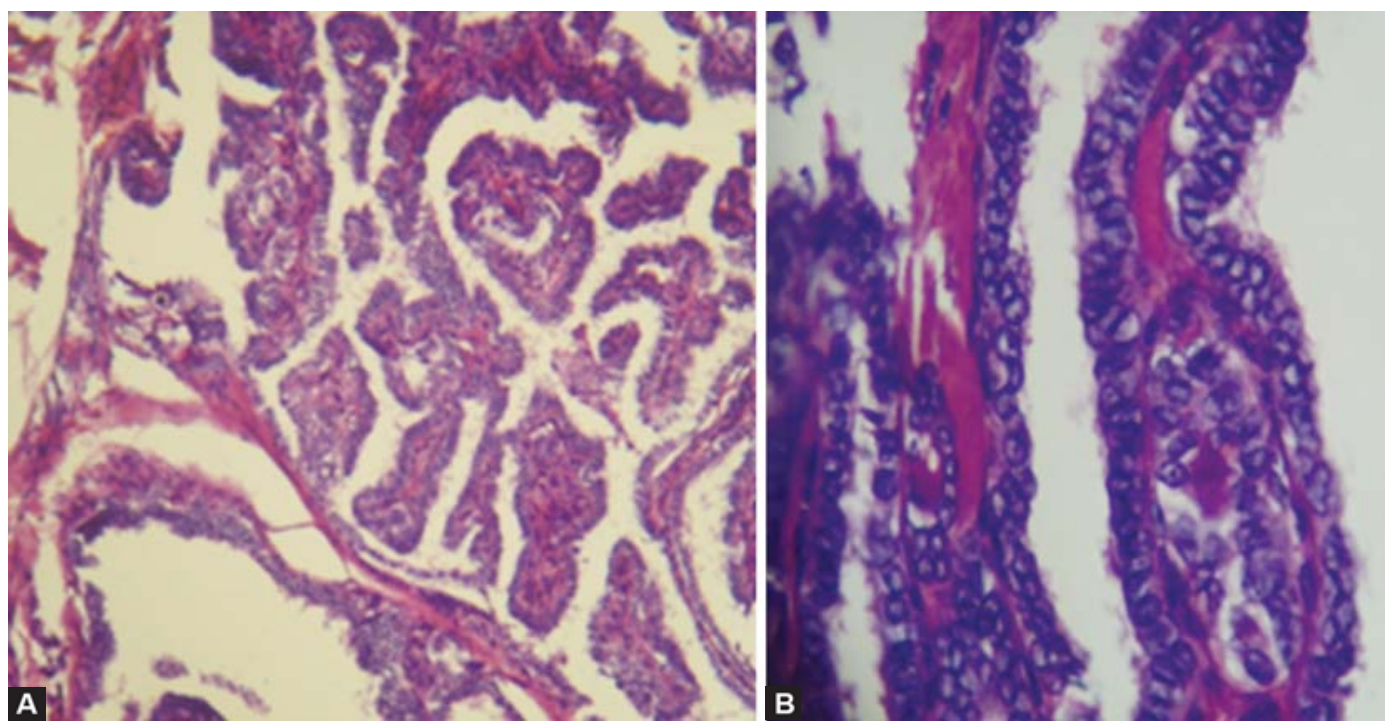

Figs 2A and B: $(A) \times 100$ low power view showing papillae with cystic areas $(B) \times 400$ high power view showing nuclear features of papillary carcinoma

Thyroglossal cysts present as small, spherical nontender midline neck swellings which are usually asymptomatic. Sometimes they may be inflamed due to infection; or discharging if previous incision drainage has been attempted. Carcinomas in thyroglossal cyst are generally not suspected preoperatively and are clinically indistinguishable from benign thyroglossal cyst. However, a thyroglossal cyst which is hard, fixed or has shown a recent increase in size should be considered suspicious. History of previous radiation to head and neck should also be considered as a risk factor.

Preoperative workup of a clinically diagnosed thyroglossal cyst should include a FNAC and thyroid profile. Ultrasound neck should be done to assess the position and parenchyma of normal thyroid gland. On ultrasound, thyroglossal cyst will appear as anechoic, hypoechoic or heterogeneous lesions, whereas thyroglossal cyst carcinoma may present as a mural lesion of the cyst with irregular 
margins or as a solid nodule in the cyst, sometimes with microcalcifications. Radioiodine thyroid scan is not recommended for routine cases but in patients with abnormal thyroid function tests and those in whom the normal location of the thyroid gland cannot be detected by ultrasonography. ${ }^{5}$

The computed tomographic (CT) scan must be carried out for a solid cyst, deep-fixed and with associated adenopathy and may reveal the presence of hypodense masses and calcifications (markers of papillary carcinoma) which can be found on a simple cervical profile X-ray also. The FNAC can point out to malignancy, but the rate of true positive is only $53 \% .{ }^{6}$ The three diagnostic criteria of papillary carcinoma on TDC are: histological identification of the thyroglossal cyst (presence of thyroid follicles in the wall of the cyst), the existence of normal thyroid tissue adjacent to the tumor and the absence of primary carcinoma in the thyroid body. ${ }^{7}$

The surgical management of thyroglossal cyst carcinoma is controversial. Some surgeons prefer to perform a total thyroidectomy in such cases based on the fact that finding papillary carcinoma in thyroglossal remnants raises the possibility of an occult primary carcinoma in the thyroid. Multifocal origin of papillary carcinoma lends support to this argument. Most of the noncontiguous tumor foci are microscopic ( $<1 \mathrm{~cm}$ in diameter). The origin of these foci is unknown. They may be intraglandular metastases of a single dominant tumor, or they may arise from unrelated neoplastic clones as demonstrated by molecular analysis of DNA extracted from distinct foci of multicentric papillary carcinomas. ${ }^{8}$ Some authors consider that patent thyroglossal cyst can be a route for metastatic involvement from the thyroid gland and that such a finding always indicates that carcinoma is present in the thyroid itself or that the cyst represents a cystic area of a papillary carcinoma in the ectopic thyroid gland. Consequently, they recommend total thyroidectomy as treatment. Others believe that papillary carcinoma found in a cystic lesion of the midline neck may actually arise in ectopic thyroid tissue and that total thyroidectomy might not be necessary as a routine procedure.

Role of postsurgical treatment with suppressive doses of thyroid hormones is also debatable.

The prognosis of papillary carcinoma arising in thyroglossal cyst is excellent, with an overall survival rate of $95.6 \%$ at 10 years. $^{9}$

\section{CONCLUSION}

In a case of microscopic carcinomatous foci without invasion of the wall of the cyst, complete excision using Sistrunk operation is sufficient. However, total thyroidectomy followed by radioactive iodine with or without hormonal suppression therapy is recommended in following cases: carcinomatous foci involving cyst wall, patients with cervical metastases, thyroid gland abnormality detected on FNAC, imaging (ultrasound or CT) or scintigraphy, when regular follow-up cannot be ensured and patient preference.

\section{REFERENCES}

1. Datar S, Patanakar T, Armao D, Mukherji SK. Papillary carcinoma in a giant thyroglossal duct cyst. Clin Imaging 2000; 24(2):75-77.

2. Ambrosi A, Fersini A, Tartaglia N, de Fazio M, Cignarelli M, Neri V. Papillary carcinoma of the thyroglossal duct cyst: a case report. G Chir 2002,23:129-133.

3. Martin-Perez E, Larranaga E, Marron C, Monje F. Primary papillary carcinoma arising in a thyroglossal duct cyst. Eur J Surg 1997 Feb;163(2):143-145.

4. Plaza CP, López ME, Carrasco CE, Meseguer LM, Perucho Ade L. Management of well-differentiated thyroglossal remnant thyroid carcinoma: time to close the debate? Report of five new cases and proposal of a definitive algorithm for treatment. Ann Surg Oncol 2006;13(5):745-752.

5. Kessler A, Eviatar E, Lapinsky J, Horne T, Shlamkovitch N, Segal S. Thyroglossal duct cyst: is thyroid scanning necessary in the preoperative evaluation? IMAJ 2001;3:409-410.

6. Yang Yl, Haghir S, Wanamaker JR, Powers CN. Diagnosis of papillary carcinoma in a thyroglossal duct cyst by fine needle aspiration biopsy. Arch Pathol Lab Med 2000;124(1):139-142.

7. Windström A, Magnusson P, Hallberg O, Hellqvist H, Riiber $\mathrm{H}$. Adenocarcinoma originating in the thyroglossal duct. Ann Otol Rhino Laryngol 1976;85(2 Pt 1):286-290.

8. Giannini R, Ugolini C, Lupi C, Proietti A, Elisei R, Salvatore G, Berti P, Materazzi G, Miccoli P, Santoro M, et al. The heterogeneous distribution of BRAF mutation supports the independent clonal origin of distinct tumor foci in multifocal papillary thyroid carcinoma. J Clin Endocrinol Metab 2007;92:3511-3516.

9. Patel SG, Escrig M, Shaha AR, Singh B, Shah JP. Management of well-differentiated thyroid carcinoma presenting within a thyroglossal duct cyst. J Surg Oncol 2002;79:134-139.

\section{ABOUT THE AUTHORS}

\section{Manish Munjal (Corresponding Author)}

Professor, Department of Otolaryngology and Head and Neck Surgery Dayanand Medical College and Hospital, Ludhiana, Punjab, India Phone: 9814323482, e-mail: manishmunjaldr@yahoo.co.in

\section{Bhawna Garg}

Assistant Professor, Department of Pathology, Dayanand Medical College and Hospital, Ludhiana, Punjab, India

\section{Neena Sood}

Professor, Department of Pathology, Dayanand Medical College and Hospital, Ludhiana, Punjab, India

\section{Vikram Bhardwaj}

Senior Resident, Department of Otolaryngology and Head and Neck Surgery, Dayanand Medical College and Hospital, Ludhiana, Punjab India 